\title{
Femur-fibula-ulna complex
}

INSERM

\section{Source}

INSERM. (1999). Orphanet: an online rare disease and orphan drug data base. Femurfibula-ulna complex. ORPHA:2019

Femur-fibula-ulna (FFU) complex is a non-lethal congenital anomaly of unknown etiology, more frequently reported in males than females, characterized by a highly variable combination of defects of the femur, fibula, and/or ulna, with striking asymmetry, including absence of the proximal part of the femur, absence of the fibula and malformation of the ulnar side of the upper limb. Axial skeleton, internal org ans and intellectual function are usually normal. 